\title{
Assessing the Effectiveness of Strategies in US Birth Cohort Screening for Hepatitis C Infection
}

\author{
Cynthia J. Tsay ${ }^{1}$ and Joseph K. Lim*2 \\ ${ }^{1}$ Department of Internal Medicine, Yale University School of Medicine, New Haven, CT, USA; ${ }^{2}$ Yale Liver Center, Section of \\ Digestive Diseases, Yale University School of Medicine, New Haven, CT, USA
}

\begin{abstract}
Chronic hepatitis $C$ infection in the USA is a highly morbid condition and current guidelines recommend one-time screening among the birth cohort (1945-1965). Understanding strategies to optimize screening can help inform future hepatitis $\mathrm{C}$ virus (HCV) screening guidelines. A focused literature search was performed using PubMed and manual abstract review from major hepatology conferences over the past 2 years. The search strategy involved using Medical Subject Headings terms for hepatitis C, screening, birth cohort, baby boomers, and 1945-1965. The review was limited to data from the USA. A total of 327 articles were identified and 36 abstracts were included, with studies published between 2012-2019. Strategies including clinician education, electronic medical record alerts, reflex HCV RNA testing, point-of-care testing, multisite (outpatient, inpatient, emergency department, endoscopy suite) initiatives, direct patient solicitation, and utilization of non-physician providers have increased HCV screening rates. However, broad implementation remains less than optimal. Barriers include lack of patient acceptance to screening and engagement in the HCV care cascade. The Veterans Affairs Healthcare System has achieved higher birth cohort screening rates through an integrated approach requiring high-level engagement by leadership and institutional commitment. Multiple strategies for increasing birth cohort screening have been successful, but overall rates of HCV screening remain low. These strategies can inform public health efforts to implement emerging national recommendations for expansion of HCV screening to all U.S. adults age 18 or older.
\end{abstract}

Citation of this article: Tsay CJ, Lim JK. Assessing the effectiveness of strategies in US birth cohort screening for hepatitis C infection. J Clin Transl Hepatol 2020;8(1):25-41. doi: 10.14218/JCTH.2019.00059.

Keywords: Hepatitis C; Epidemiology; HCV antibody; Screening; Birth cohort; Baby boomers; Care cascade; Electronic medical records.

Abbreviations: $A b$, antibody; BPAs, best practice alerts; $C D C$, Center for Disease Control; DAAs, direct acting antivirals; ED, emergency department; EMR, electronic medical record; HCV, hepatitis C virus; NHANES, National Health and Nutrition Examination Survey; POCT, point-of-care testing; RDT, rapid detecting test; USPSTF, USA Preventative Services Task Force; VHA, Veterans Health Administration.

Received: 18 December 2019; Revised: 4 February 2020; Accepted: 25 February 2020

*Correspondence to: Joseph K. Lim, Yale Liver Center, Section of Digestive Diseases, Yale University School of Medicine, 333 Cedar Street, LMP 1080, New Haven, CT 06520-8019, USA. Tel: +1- 203-737-6063, Fax: +1-203-785-7273, E-mail: joseph.lim@yale.edu

\section{Introduction}

Chronic hepatitis $\mathrm{C}$ virus (HCV) infection is one of the most common indications for liver transplantation and the leading cause of hepatocellular carcinoma in the USA, accounting for approximately 19,000 deaths annually and substantial healthcare costs. ${ }^{1}$ An estimated 4.1 million individuals in the USA are HCV antibody (Ab)-positive, indicative of past or current infection. Among those, approximately 2.4 million individuals have ongoing chronic $\mathrm{HCV}$ infection with positive HCV RNA. ${ }^{2}$ The baby boomer "birth cohort" of individuals born 1945-1965 comprise approximately $75 \%$ of HCV infections in the USA despite representing only $27 \%$ of the general population. ${ }^{3}$ One study in 2012 retrospectively applied birth cohort to previously risk-based HCV screening using the National Health and Nutrition Examination Survey (NHANES) database and determined that optimal application of risk-based guidelines would identify $82 \%$ of chronic HCV cases (number needed to screen 14.6) compared to birth-cohort screening, which would identify $76 \%$ of chronic HCV cases (number needed to screen 28.7$){ }^{4}$

The Center for Disease Control (CDC) and the USA Preventative Services Task Force (USPSTF) issued recommendations in $2012^{3,5}$ and $2013^{6,7}$ recommending one-time universal screening in all individuals born between 19451965 , irrespective of symptoms or risk factors. Cost effectiveness studies have confirmed birth cohort screening to be cost saving for billions in test and treat models. ${ }^{5}$ However, recent studies indicate that HCV testing in the birth cohort minimally increased from $12.3 \%$ to $17.3 \%$ between 2013 and 2017.8 One unique population, veterans being cared for at the Veteran Affairs Healthcare System, achieved more successful screening through automated clinical reminders through the electronic medical record (EMR) and also increased awareness among primary care providers through national directives. One study reported $79.5 \%$ of veterans born between 1945-1965 had been tested for the HCV Ab. ${ }^{9}$

Given the high cost and mortality associated with HCV, coupled with the presence of effective treatment options with direct-acting antivirals (DAAs), identification of patients with $\mathrm{HCV}$ is of paramount importance to public health efforts to achieve HCV elimination. The success of the World Health Organization campaign for global elimination of HCV infection by $2030^{10,11}$ will depend on optimization of the HCV care cascade from screening/identification to linkage to treatment, ${ }^{12}$ and the associated funding required to support hepatitis programs. ${ }^{13}$

This review summarizes existing strategies for increasing the screening or testing of HCV infection within the birth 
cohort (1945-1965). Although there have been substantial efforts on HCV microelimination in several global regions, this article focuses primarily on evidence from the USA. Understanding existing strategies for optimization of 1945-1965 birth cohort screening may help inform future guidelines for public health interventions focused on HCV screening, particularly in the context of the burgeoning opioid epidemic.

\section{Methods}

A focused literature search was performed using PubMed, with a combination of search terms, including screen, test, hepatitis C virus, HCV, hepatitis C, birth cohort, 1945-1965, and baby boomer, in August 2019. Manual abstract review was performed (C.T.) for major hepatology conferences, including The Liver Meeting 2017-2018 of the American Association for the Study of Liver Diseases, Digestive Diseases Week 2017-2019, and The International Liver Congress of the European Association for the Study of the Liver 20172019. The review was limited to USA data, with the exception of reports from six countries (Argentina, Chile, Finland, France, Greece, and Japan $)^{14}$ with similar recommendations for birth cohort screening or one-time screening for all ages. There was no time restriction imposed on the search strategy of original manuscripts.

\section{Results}

A total of 327 full text papers were identified by the database search and an additional 38 abstracts per manual review from major conferences. After individual assessment of abstracts, 36 were included in the review. Study characteristics and outcomes are summarized below (Table 1 ). All papers were published 2012-2019 but one study from 2012 was excluded due to assessment prior to implementation of CDC birth cohort recommendations. ${ }^{15}$

\section{Current state of hepatitis C screening in the USA}

The current recommendations of the CDC and USPTF regarding HCV screening are summarized as follows:

CDC (August 17, 2012): In addition to testing adults of all ages at risk for HCV infection, the CDC recommends:

- All adults born during 1945-1965 receive one-time testing for the HCV.

- Testing should begin with anti-HCV. If the anti-HCV test is positive, or reactive, then a nucleic acid test should follow.

- All persons identified with current HCV infection should receive a brief alcohol screening and intervention, as clinically indicated, followed by referral to appropriate care and treatment services. ${ }^{5}$

\section{USPSTF (June 25, 2013) recommends:}

- Screening for HCV infection in persons at high risk for infection.

- One-time screening for HCV infection in adults born between 1945 and 1965.

These recommendations were in line with recommendations of the Institute of Medicine and the USA Department of Health and Human Services Action Plan for the Prevention,
Care and Treatment of Viral Hepatitis. ${ }^{16}$ Subsequent studies confirmed the cost-effectiveness of birth cohort testing based on health economic models, which projected that an additional 808,580 cases of chronic HCV infection cases would be identified at a cost of $\$ 2874$ per case, and that even with a test-and-treat strategy using historical DAA plus pegylated interferon/ribavirin, quality adjusted life-years increased by $\$ 532,000$, with an incremental cost-effectiveness ratio of $\$ 35,700$ per quality adjusted life-years saved. ${ }^{17}$

Despite implementation of these recommendations in 2012-2013, a recent review suggested that there was only a modest increase in HCV screening within the birth cohort in the USA, estimated to have risen from $12.3 \%$ in 2013 to $17.3 \%$ in $2017 .^{8}$ Further analysis of this dataset identified the primary care clinic as the setting in which prioritization of testing should occur, permitting unscreened or untested eligible patients access to follow-up care within the outpatient clinic. ${ }^{18}$ This information underlines the need for more innovative screening strategies to be implemented which involve a combination of patient and provider education, harnessing the electronic health record automated alerts in the inpatient, outpatient, emergency departments, endoscopy, and colonoscopy suites, as well as a patient-centered medical home approach $^{19}$ utilizing non-physician providers to assist in improving screening, reflex testing, and linkage of care to the HCV care cascade.

\section{Innovative strategies for screening}

\section{EMR alerts}

The advent of the EMR or electronic health record has created a platform in which screening can become more streamlined with patient care in both the outpatient and inpatient settings. Additionally, several states, including New York, Connecticut, Massachusetts, California, and Colorado, have established laws mandating that baby boomers be offered screening with a one-time HCV Ab test. In New York state, laboratory data confirmed a $51 \%$ increase in the number of specimens collected for HCV testing among birth cohort individuals between 2013 and 2014, and New York Medicaid data revealed a $52 \%$ increase in average monthly testing for $\mathrm{HCV}$ $\mathrm{Ab}$ from 2012 to $2014^{20}$ despite exclusion of HCV testing requirement in the emergency department (ED) setting. ${ }^{21}$

Furthermore, while EMR appears to be a cornerstone for automated alerts, given the simplicity of identifying screening candidates based solely on date of birth, additional strategies to augment EMR-based testing have resulted in significant increases in screening rates, including one study employing targeted education of resident physicians which found an increase from $62 \%$ at baseline to $81 \%$ at 6 months postintervention. ${ }^{22}$ Similar increases in screening rates employing education plus EMR reminders in a resident physician context resulted in up to a 3 -fold increase in HCV testing rates. ${ }^{23-24}$

\section{Outpatient}

Primary care and outpatient specialty clinics are the cornerstone of population-based screening and the focus of most EMR alert-based interventions. Multiple studies have reported increases in HCV screening rates after implementation of EMR alerts $^{25-31}$ in multiple quality improvement interventions, including those incorporating formal Plan, Do, Study, Act cycles; although, the magnitude of increase has ranged 
Tsay C.J. et al: Birth cohort screening for HCV

Table 1. Characteristics and outcomes from HCV screening strategies among birth cohort individuals

\begin{tabular}{|c|c|c|c|c|c|c|}
\hline Study & Type & Design & Population & Setting & Sample size & Outcomes \\
\hline \multicolumn{7}{|l|}{ EMR alerts } \\
\hline \multicolumn{7}{|l|}{ Outpatient } \\
\hline Jones (2017) & Abstract & $\begin{array}{l}\text { Retrospective } \\
\text { chart review }\end{array}$ & $\begin{array}{l}\text { Patients born } \\
\text { between } 1945- \\
1965 \text { not previously } \\
\text { screened for HCV }\end{array}$ & $\begin{array}{l}\text { Baylor Scott \& } \\
\text { White in Central } \\
\text { Texas Primary Care } \\
\text { Clinic from 2/ } \\
2014-2 / 2015\end{array}$ & $n>30,000$ & $\begin{array}{l}\text { Statistically } \\
\text { significant increase } \\
\text { in baby-boomer } \\
\text { screening for } \\
\text { hepatitis C from } \\
1.87 \% \text { prior to } \\
\text { EMR reminder to } \\
14.14 \% \text { after } \\
\text { initiation of the } \\
\text { reminder }\end{array}$ \\
\hline Kahn (2018) & Abstract & $\begin{array}{l}\text { Retrospective } \\
\text { chart review }\end{array}$ & $\begin{array}{l}\text { Patients born } \\
\text { between } 1945- \\
1965 \text { not previously } \\
\text { screened for HCV }\end{array}$ & $\begin{array}{l}\text { Northshore } \\
\text { University Health } \\
\text { System; } \\
\text { Implemented 7/ } \\
2017\end{array}$ & $n=99892$ & $\begin{array}{l}\text { HCV tested: } \\
13.8 \%(13,804 / \\
99,892) \text { Highly } \\
\text { varied adherence } \\
\text { to screening } \\
\text { guidelines by PCPs }\end{array}$ \\
\hline $\begin{array}{l}\text { Konerman } \\
\text { (2017) }\end{array}$ & Abstract & $\begin{array}{l}\text { Retrospective } \\
\text { cohort study }\end{array}$ & $\begin{array}{l}\text { Patients born } \\
\text { between 1945- } \\
1965 \text { without prior } \\
\text { diagnosis of HCV } \\
\text { infection, no prior } \\
\text { documented anti- } \\
\text { HCV testing }\end{array}$ & $\begin{array}{l}\text { Primary care } \\
\text { clinics }\end{array}$ & $n=52,5660$ & $\begin{array}{l}\text { HCV screening } \\
\text { increased } 10 \text {-fold } \\
\text { from } 7.6 \% \text { for } \\
\text { patients with PCP } \\
\text { visit in } 6 \text { months } \\
\text { prior to BPA } \\
\text { implementation to } \\
72 \% \text { over a } 1 \text {-year } \\
\text { period after } \\
\text { implementation }\end{array}$ \\
\hline Soo (2017) & Abstract & $\begin{array}{l}\text { Retrospective } \\
\text { chart review }\end{array}$ & $\begin{array}{l}\text { Patients born } \\
\text { between 1945- } \\
1965 . \text { Excluded } \\
\text { patients with HCV } \\
\text { on problem list or if } \\
\text { they had their one- } \\
\text { time HCV screen }\end{array}$ & $\begin{array}{l}\text { Automatic health } \\
\text { maintenance alert } \\
\text { in an integrated } \\
\text { medical group, 6/ } \\
2015-6 / 2016\end{array}$ & $n=29,987$ & $\begin{array}{l}\text { HCV screening rate } \\
\text { increased from } \\
\text { baseline } 13.3 \% \text { to } \\
15.6 \% \text { after } 1 \\
\text { month and to } \\
40.2 \% \text { after } 12 \\
\text { months HCV Ab- } \\
\text { positive: } 2.3 \% \\
(684 / 29987)\end{array}$ \\
\hline Soo (2018) & Abstract & $\begin{array}{l}\text { Prospective } \\
\text { cohort }\end{array}$ & $\begin{array}{l}\text { Patients born } \\
\text { between 1945- } \\
1965 \text {. Excluded } \\
\text { patients with HCV } \\
\text { on problem list } \\
\text { based on ICD9/10 } \\
\text { code or positive } \\
\text { anti-HCV or HCV } \\
\text { RNA }\end{array}$ & $\begin{array}{l}\text { Automatic health } \\
\text { maintenance alert } \\
\text { module at primary } \\
\text { care practices in } \\
\text { the Providence } \\
\text { Health and } \\
\text { Services and rates } \\
\text { assessed monthly } \\
\text { in five regions in } \\
\text { the Western USA, } \\
1 / 2017 \text { - } 12 / 2018\end{array}$ & $n=76288$ & $\begin{array}{l}\text { HCV Ab-positive: } \\
4.6 \%(3507 / \\
76,288) ; \mathrm{HCV} \\
\text { screening rate } \\
\text { increased } 31.9 \% \\
\text { from } 23.0 \% \text { to } \\
54.9 \%\end{array}$ \\
\hline
\end{tabular}


Tsay C.J. et al: Birth cohort screening for HCV

Table 1. (continued)

\begin{tabular}{|c|c|c|c|c|c|c|}
\hline Study & Type & Design & Population & Setting & Sample size & Outcomes \\
\hline Teply (2018) & Abstract & $\begin{array}{l}\text { Retrospective } \\
\text { chart review }\end{array}$ & $\begin{array}{l}\text { All patients born } \\
\text { between } 1945- \\
1965 \text { seen at a } \\
\text { primary care clinic } \\
\text { within a regional } \\
\text { healthcare system } \\
\text { in Midwest USA }\end{array}$ & $\begin{array}{l}35 \text { primary care } \\
\text { clinics within a } \\
\text { regional } \\
\text { healthcare system } \\
\text { in Midwest USA } \\
\text { (prealert), 6/1/ } \\
2016-11 / 30 / \\
2016 ; \text { (postalert) } \\
12 / 1 / 2016-5 / 31 / \\
2017\end{array}$ & $\begin{array}{l}\mathrm{n}=29,703 \\
\text { (pre), 29,913 } \\
\text { (post) }\end{array}$ & $\begin{array}{l}\text { Prealert HCV } \\
\text { tested: } 1.62 \% \\
\text { (482/29.703) HCV } \\
\text { Ab-positive: } 4.2 \% \\
\text { (20/482) Postalert } \\
\text { HCV tested: } \\
19.0 \%(5685 / \\
29,913) \text { HCV Ab- } \\
\text { positive: } 1.9 \% \\
(107 / 5685) 10- \\
\text { fold increase in } \\
\text { HCV screening }\end{array}$ \\
\hline Al-Hihi (2017) & $\begin{array}{l}\text { Full- } \\
\text { text }\end{array}$ & $\begin{array}{l}\text { Prospective } \\
\text { cohort- } 2 \text { PDSA } \\
\text { cycles }\end{array}$ & $\begin{array}{l}\text { All patients born } \\
\text { between 1945- } \\
1965 \text { seen in a } \\
\text { primary care clinic }\end{array}$ & $\begin{array}{l}\text { Multiphysician } \\
\text { practice in the } \\
\text { Midwest USA } \\
\text { representing } 84 \\
\text { faculty physicians } \\
\text { and residents, 6/ } \\
2016-3 / 2017, \text { with } \\
\text { BPA and health } \\
\text { maintenance alerts } \\
\text { in the EMR and } \\
\text { education to } \\
\text { primary care } \\
\text { providers via } \\
\text { single educational } \\
\text { sessions with a } \\
\text { hepatologist }\end{array}$ & Not reported & $\begin{array}{l}\text { Baseline screening } \\
\text { rate } \\
\text { preintervention: } \\
30 \%(1674 / 5541) \\
\text { Screening rate at } 3 \\
\text { mo: } 45 \% \\
\text { Screening rate } 3 \\
\text { mo after } \\
\text { concurrent } \\
\text { education session: } \\
55 \%\end{array}$ \\
\hline $\begin{array}{l}\text { Federman } \\
\text { (2017) }\end{array}$ & $\begin{array}{l}\text { Full- } \\
\text { text }\end{array}$ & $\begin{array}{l}\text { Randomized } \\
\text { control trial }\end{array}$ & $\begin{array}{l}\text { Patients born } \\
\text { during birth cohort } \\
\text { period were } \\
\text { subjects. However, } \\
\text { attending } \\
\text { physicians and } \\
\text { medical residents } \\
\text { were participants in } \\
\text { the study to see } \\
\text { how BPA affected } \\
\text { HCV testing and } \\
\text { incidence of HCV } \\
\text { Ab-positive tests }\end{array}$ & $\begin{array}{l}10 \text { community and } \\
\text { hospital-based } \\
\text { primary care } \\
\text { practices that } \\
\text { implemented BPA } \\
\text { for HCV testing } \\
\text { among birth cohort } \\
\text { adults, } 4 / 2013-3 / \\
2014\end{array}$ & $\begin{array}{l}\mathrm{n}=25,620 \\
\text { study-eligible } \\
\text { visits }\end{array}$ & $\begin{array}{l}\text { Testing rates } \\
\text { greater among } \\
\text { Birth Cohort pts in } \\
\text { intervention sites } \\
(20.2 \% \vee 1.8 \% \text {, } \\
\mathrm{p}<0.0001) \mathrm{EHR}- \\
\text { embedded BPA } \\
\text { markedly } \\
\text { increased HCV } \\
\text { screening, but the } \\
\text { majority of eligible } \\
\text { pts did not receive } \\
\text { testing indicating a } \\
\text { need for more } \\
\text { effective methods } \\
\text { to promote uptake }\end{array}$ \\
\hline $\begin{array}{l}\text { Nitsche } \\
\text { (2018) }\end{array}$ & Full Text & Case control & $\begin{array}{l}\text { Patients born } \\
\text { between } 1945- \\
1965\end{array}$ & $\begin{array}{l}7 \text { primary care } \\
\text { sites in Virginia } \\
\text { Mason Healthcare } \\
\text { System (greater } \\
\text { Seattle area, WA), } \\
8 / 1 / 2014-9 / 14 / \\
2015 \text { with } 3 \text { sites } \\
\text { given additional } \\
\text { education } \\
\text { interventions } \\
\text { (case) not } \\
\text { provided to the } \\
\text { remaining } 4 \\
\text { (control) }\end{array}$ & $\begin{array}{l}n=73,685 ; \\
\text { cases } 37,783 ; \\
\text { controls } \\
35,902\end{array}$ & $\begin{array}{l}\text { Screening rates at } \\
\text { the following times } \\
\text { (case vs. control), } \\
p<0.001 \text { at all time } \\
\text { points Baseline: } \\
6.1 \% \text { vs. } 4.6 \% \\
\text { Time } 1: 18.1 \% \text { vs. } \\
10.4 \% \text { Time } 2: \\
20.3 \% \text { vs. } 12.5 \% \\
\text { Time } 3: 22.2 \% \text { vs. } \\
13.7 \% \text { Time } 4: \\
23.4 \% \text { vs. } 14.7 \% \\
\text { Time } 5: 24.2 \% \text { vs. } \\
15.3 \% \text { Time } 6: \\
17.5 \% \text { vs. } 10.4 \%\end{array}$ \\
\hline
\end{tabular}


Tsay C.J. et al: Birth cohort screening for HCV

Table 1. (continued)

\begin{tabular}{|c|c|c|c|c|c|c|}
\hline Study & Type & Design & Population & Setting & Sample size & Outcomes \\
\hline $\begin{array}{l}\text { Shahnazarian } \\
\text { (2015) }\end{array}$ & $\begin{array}{l}\text { Full- } \\
\text { text }\end{array}$ & Case control & $\begin{array}{l}\text { Patients born } \\
\text { between 1945- } \\
1965\end{array}$ & $\begin{array}{l}\text { Methodist Hospital } \\
\text { in Brooklyn, NY } \\
\text { prelegislative } \\
\text { mandate (12/ } \\
2013) \text { and } \\
\text { postmandate and } \\
\text { postEMR } \\
\text { intervention, 5/ } \\
2014-2 / 2015\end{array}$ & Not reported & $\begin{array}{l}\text { PreEMR alert HCV } \\
\text { screen: } 47.2 \% \\
\text { PostEMR alert HCV } \\
\text { screen: } 87.9 \%\end{array}$ \\
\hline $\begin{array}{l}\text { Yeboah- } \\
\text { Korang (2018) }\end{array}$ & $\begin{array}{l}\text { Full- } \\
\text { text }\end{array}$ & Case control & $\begin{array}{l}\text { Patients born } \\
\text { between } 1945- \\
1965 \text { in the } \\
\text { outpatient setting }\end{array}$ & $\begin{array}{l}\text { Northshore } \\
\text { University Health } \\
\text { System, } 1 / 2010 \text { to } \\
12 / 2015 \text {, with } \\
\text { retrospective chart } \\
\text { review back to } \\
2003 \text { to identify } \\
\text { overall HCV testing } \\
\text { rates (case) and } \\
\text { then during } 7 / \\
2015 ; \text { BPA alert } \\
\text { implemented } 7 / \\
2017-11 / 2017\end{array}$ & $\begin{array}{l}n=10,089 \\
\text { (pre); 45,188 } \\
\text { (post) }\end{array}$ & $\begin{array}{l}\text { PreEMR alert HCV } \\
\text { screen: } 0.68 \% \\
(69 / 10,089) \\
\text { PostEMR alert HCV } \\
\text { screen: } 10.76 \% \\
(5451 / 45,188) \\
15.8 \text {-fold increase } \\
\text { in HCV testing } \\
\text { rates }\end{array}$ \\
\hline \multicolumn{7}{|l|}{ Inpatient } \\
\hline Mehta (2017) & Abstract & $\begin{array}{l}\text { Retrospective } \\
\text { cohort }\end{array}$ & $\begin{array}{l}\text { Adult admitted to } \\
\text { inpatient medicine } \\
\text { service born } \\
\text { between } 1945- \\
1965\end{array}$ & $9 / 2014-9 / 2016$ & $n=1128$ & $\begin{array}{l}\text { HCV Ab-positive: } \\
\text { 9.6\% (108/1128) } \\
\text { HCV-positive: 52\% } \\
\text { (56/108) HCV RNA } \\
\text { PCR-positive : } \\
\text { 21\% HCV RNA } \\
\text { PCR-negative: } \\
\text { 25\% HCV RNA PCR } \\
\text { not performed } \\
\text { during } \\
\text { hospitalization: } \\
54 \% \text { Only 18\% of } \\
\text { seropositive had } \\
\text { outpatient } \\
\text { gastrointestinal } \\
\text { follow-up }\end{array}$ \\
\hline Shen (2018) & Abstract & $\begin{array}{l}\text { Retrospective } \\
\text { cohort }\end{array}$ & $\begin{array}{l}\text { Patients born } \\
\text { between 1945- } \\
1965 \text { categorized } \\
\text { by } 3 \text { timeframes } \\
\text { (premandate, } \\
\text { postmandate but } \\
\text { prereflex RNA, } \\
\text { postreflex RNA) } \\
\text { and stratified by } \\
\text { screened vs not } \\
\text { screened }\end{array}$ & $\begin{array}{l}\text { Patients admitted } \\
\text { to New York } \\
\text { Presbyterian } \\
\text { Hospital- Weill } \\
\text { Cornell; data } \\
\text { collected in } 3 \text { times } \\
\text { frames: } 1 . \\
\text { Premandate (1/ } \\
2013-12 / 2013) 2 \text {. } \\
\text { Postmandate but } \\
\text { prereflex ( } 1 / 2014- \\
8 / 2015) 3 \text {. } \\
\text { Postreflex RNA (9/ } \\
2015-12 / 2016)\end{array}$ & $n=51657$ & $\begin{array}{l}\text { Overall and initial } \\
\text { screening } \\
\text { improved pre- and } \\
\text { postmandate from } \\
8 \% \text { to } 39 \% \text { and } \\
53 \% \text { to } 84 \% \\
(p<0.01) ; \text { this did } \\
\text { not translate into } \\
\text { improved linkage } \\
\text { to care Follow-up } \\
\text { care and initiation } \\
\text { of treatment } \\
\text { decreased from } \\
31 \% \text { to } 20 \% \text { and } \\
9 \% \text { to } 5 \% \text {, } \\
(p<0.01)\end{array}$ \\
\hline
\end{tabular}


Tsay C.J. et al: Birth cohort screening for HCV

Table 1. (continued)

\begin{tabular}{|c|c|c|c|c|c|c|}
\hline Study & Type & Design & Population & Setting & Sample size & Outcomes \\
\hline Turner (2015) & $\begin{array}{l}\text { Full- } \\
\text { text }\end{array}$ & $\begin{array}{l}\text { Prospective } \\
\text { cohort }\end{array}$ & $\begin{array}{l}\text { Patients born } \\
\text { between 1945- } \\
1965 \text { admitted to } \\
\text { hospital }\end{array}$ & $\begin{array}{l}\text { Safety-net hospital } \\
\text { in South Texas } \\
\text { from } 1 / 2012-1 / \\
2014 \text { with follow- } \\
\text { up through } 12 \text { / } \\
2014\end{array}$ & $n=6140$ & $\begin{array}{l}\text { HCV tested: } 51 \% \\
\text { (3168/6140) HCV } \\
\text { Ab-positive: } 7.6 \% \\
\text { (240/3168) HCV } \\
\text { RNA-positive: } 63 \% \\
(134 / 214), 4.2 \% \\
\text { overall chronic } \\
\text { HCV: } 96.3 \% \text { (129/ } \\
134) \text { were } \\
\text { counseled and } \\
80.6 \% \text { (108/134) } \\
\text { received primary } \\
\text { care follow-up and } \\
38.8 \% \text { (52/134) } \\
\text { received } \\
\text { hepatology follow- } \\
\text { up with } 5 \text { initiating } \\
\text { anti-HCV } \\
\text { treatment }\end{array}$ \\
\hline \multicolumn{7}{|c|}{$\begin{array}{c}\text { Direct patient solicitation- phone call, } \\
\text { mailing }\end{array}$} \\
\hline Trowell (2018) & Abstract & $\begin{array}{l}\text { Prospective } \\
\text { cohort }\end{array}$ & $\begin{array}{l}\text { Patients born } \\
\text { between 1945- } \\
1965 \text { chosen from a } \\
\text { population in a } \\
\text { Baltimore city } \\
\text { hospital }\end{array}$ & $\begin{array}{l}\text { Two-pronged } \\
\text { approach: } 1 . \text { BPA } \\
\text { created in EMR to } \\
\text { prompt PCP to } \\
\text { order tests for } \\
\text { patients; } 2 \text {. Letters } \\
\text { mailed with } \\
\text { educational } \\
\text { material, blood } \\
\text { test request forms } \\
\text { for pts without } \\
\text { prior HCV testing }\end{array}$ & $n=15,583$ & $\begin{array}{l}\text { BPA screened } \\
8786 / 15,583 \\
\text { Letters screened } \\
3645 / 15,583 \\
\text { Screened via } \\
\text { hospital or other } \\
\text { affiliated locations } \\
3152 / 15,583 \mathrm{HCV} \\
\text { Ab-positive: } 2.7 \% \\
(426 / 15,583) \mathrm{HCV} \\
\text { RNA-positive: } \\
1.3 \% \text { ( } 204 / \\
15,583) \text { HCV } \\
\text { positivity rates } \\
\text { highest in } 1951- \\
1960 \text { birth cohort }\end{array}$ \\
\hline Kruger (2017) & Full Text & $\begin{array}{l}\text { Prospective } \\
\text { cohort }\end{array}$ & $\begin{array}{l}\text { Project managers } \\
\text { of each of the three } \\
\text { sites implementing } \\
\text { HCV screening per } \\
\text { CDC } \\
\text { recommendation } \\
\text { (BEST-C sites). } \\
\text { Filled out } \\
\text { standardized } \\
\text { questionnaires } \\
\text { about their } \\
\text { implementation } \\
\text { experiences and } \\
\text { qualitative analysis }\end{array}$ & $\begin{array}{l}\text { Three sites } \\
\text { implemented } \\
\text { interventions to } \\
\text { increase birth- } \\
\text { cohort testing } \\
\text { through } \\
\text { participation in the } \\
\text { Birth-cohort } \\
\text { Evaluation to } \\
\text { Advance Screening } \\
\text { and Testing for } \\
\text { Hepatitis C from } \\
12 / 2012-3 / 2014\end{array}$ & Not reported & $\begin{array}{l}\text { BPA was the } \\
\text { preferred } \\
\text { intervention at all } \\
\text { three sites, but } \\
\text { site-specific } \\
\text { challenges } \\
\text { prevented success } \\
\text { of the solution in } \\
\text { two out of three } \\
\text { sites Despite } \\
\text { challenges in start- } \\
\text { up of the screening } \\
\text { in PCP settings, it } \\
\text { was deemed } \\
\text { feasible and likely } \\
\text { successful given } \\
\text { dedicated } \\
\text { resources, buy-in, } \\
\text { and support from } \\
\text { hospital } \\
\text { administration }\end{array}$ \\
\hline
\end{tabular}


Tsay C.J. et al: Birth cohort screening for HCV

Table 1. (continued)

\begin{tabular}{|c|c|c|c|c|c|c|}
\hline Study & Type & Design & Population & Setting & Sample size & Outcomes \\
\hline Yartel (2018) & $\begin{array}{l}\text { Full- } \\
\text { text }\end{array}$ & $\begin{array}{l}\text { Randomized } \\
\text { control trial }\end{array}$ & $\begin{array}{l}\text { Patients born } \\
\text { between } 1945- \\
1965 \text { not previously } \\
\text { screened or } \\
\text { diagnosed }\end{array}$ & $\begin{array}{l}\text { Patients randomly } \\
\text { assigned to receive } \\
\text { one of three } \\
\text { independent } \\
\text { implementation } \\
\text { strategies } \\
\text { (repeated mailing } \\
\text { outreach, BPA, } \\
\text { direct patient } \\
\text { solicitation), } 12 \text { / } \\
\text { 2012-3/2014 }\end{array}$ & $\begin{array}{l}n=8992 \\
\text { (mailing trial) } \\
n=14,475 \\
\text { (BPA trial) } \\
n=8873 \\
\text { (patient } \\
\text { solicitation } \\
\text { trial) }\end{array}$ & $\begin{array}{l}\text { Repeated mailing- } \\
\text { intervention was } 8 \\
\text { times as likely to } \\
\text { identify anti-HCV- } \\
\text { positive (adjusted } \\
\text { relative risk: } 8.0 \text {, } \\
95 \% \text { confidence } \\
\text { interval: } 2.8-23.0 \text {; } \\
\text { adjusted } \\
\text { probabilities: } \\
\text { intervention } \\
0.27 \%, \text { control } \\
0.03 \% \text { BPA trial } \\
\text { was } 2.6 \text { times as } \\
\text { likely to identify } \\
\text { anti-HCV-positive } \\
\text { (adjusted relative } \\
\text { risk } 2.6,95 \% \\
\text { confidence } \\
\text { interval: } 1.1-6.4 ; \\
\text { adjusted } \\
\text { probabilities: } \\
\text { intervention } \\
0.29 \%, \text { control } \\
0.11 \% \text { ) Patient- } \\
\text { solicitation trial } \\
\text { was } 5 \text { times as } \\
\text { likely to identify } \\
\text { anti-HCV-positive } \\
\text { (adjusted relative } \\
\text { risk } 5.3,95 \% \\
\text { confidence } \\
\text { interval: } 2.3-12.3 \text { ) }\end{array}$ \\
\hline \multicolumn{7}{|l|}{ Colonoscopy } \\
\hline $\begin{array}{l}\text { Abu-Heija } \\
\text { (2018) }\end{array}$ & Abstract & $\begin{array}{l}\text { Retrospective } \\
\text { chart review }\end{array}$ & $\begin{array}{l}\text { Dominantly African } \\
\text { American adults } \\
\text { undergoing } \\
\text { colonoscopy born } \\
\text { between 1945- } \\
\text { 1952, subgroup } \\
\text { analysis with } \\
\text { university physician } \\
\text { group or outsider } \\
\text { provider }\end{array}$ & $\begin{array}{l}\text { Urban open access } \\
\text { colonoscopy suite, } \\
2014\end{array}$ & $n=444$ & $\begin{array}{l}\text { HCV tested: } 140 / \\
444 \text { HCV Ab- } \\
\text { positive: } 43 \% \text { (60/ } \\
\text { 140) HCV RNA } \\
\text { PCR-positive: } 94 \% \\
\text { (56/60) university } \\
\text { physician group } \\
\text { vs. non- university } \\
\text { physician group } \\
\text { tested: } 48 \% \text { vs. } \\
15 \% \text { ( } p<0.05 \text { ) } \\
\text { Lost to follow-up } \\
\text { after first visit: } \\
47 \%\end{array}$ \\
\hline $\begin{array}{l}\text { Abu-Heija } \\
\text { (2019) }\end{array}$ & Abstract & $\begin{array}{l}\text { Retrospective } \\
\text { chart review }\end{array}$ & $\begin{array}{l}\text { Dominantly African } \\
\text { American adults } \\
\text { undergoing } \\
\text { colonoscopy born } \\
\text { between 1945- } \\
1958\end{array}$ & $\begin{array}{l}\text { Urban open access } \\
\text { colonoscopy suite } \\
\text { in } 2014 \text { or } 2017\end{array}$ & $\mathrm{n}=988$ & $\begin{array}{l}\text { HCV tested: } \\
40.3 \%(2017) \text { vs. } \\
31.5 \%(2014) \\
(p=0.005) ; \text { no } \\
\text { difference based } \\
\text { on race or gender } \\
\text { HCV Ab-positive: } \\
31.5 \%(2017) \text { vs. } \\
42.9 \%(2014) \text { HCV } \\
\text { RNA PCR-positive: } \\
97 \%(2017) \text { vs. } \\
96.5 \%\end{array}$ \\
\hline
\end{tabular}

(continued) 
Tsay C.J. et al: Birth cohort screening for HCV

Table 1. (continued)

\begin{tabular}{|c|c|c|c|c|c|c|}
\hline Study & Type & Design & Population & Setting & Sample size & Outcomes \\
\hline Matin (2018) & Abstract & $\begin{array}{l}\text { Prospective } \\
\text { cohort }\end{array}$ & $\begin{array}{l}\text { Veterans } \\
\text { undergoing } \\
\text { colonoscopy, } \\
\text { registered nurse } \\
\text { screen day prior } \\
\text { and if no prior } \\
\text { screen for HCV and } \\
\text { born between } \\
1945-1965, \text { verbal } \\
\text { consent obtained } \\
\text { over the phone, } \\
\text { HCV tested when } \\
\text { intravenous line } \\
\text { placed }\end{array}$ & $\begin{array}{l}\text { Veterans Affairs } \\
\text { facility, } 7 / 2017- \\
10 / 2017\end{array}$ & $\begin{array}{l}n=208 \text { ( } 38 \text { did } \\
\text { not show for } \\
\text { appointments) }\end{array}$ & $\begin{array}{l}\text { HCV tested: } 145 / \\
170(85 \%)\end{array}$ \\
\hline Sears (2013) & $\begin{array}{l}\text { Full- } \\
\text { text }\end{array}$ & $\begin{array}{l}\text { Prospective } \\
\text { cohort }\end{array}$ & $\begin{array}{l}\text { Adults aged } 50-65 \\
\text { years-old who } \\
\text { received a } \\
\text { colonoscopy } \\
\text { answered } \\
\text { questions in a } \\
\text { survey and blood } \\
\text { samples were } \\
\text { collected for } \\
\text { hepatitis B virus } \\
\text { and HCV }\end{array}$ & 3 month period & $n=500$ & $\begin{array}{l}\text { HCV tested: } 72 \% \\
\text { (376/500) HCV } \\
\text { Ab-positive: } 4 / 376 \\
\text { HCV RNA PCR- } \\
\text { positive: } 1 / 4\end{array}$ \\
\hline \multicolumn{7}{|l|}{ Endoscopy } \\
\hline Hirode (2018) & Abstract & $\begin{array}{l}\text { Prospective } \\
\text { cohort }\end{array}$ & $\begin{array}{l}\text { Adults undergoing } \\
\text { outpatient } \\
\text { endoscopy } \\
\text { categorized into: } 1 \text { ) } \\
\text { BC and at least one } \\
\text { RF 2) BC and no RF } \\
\text { 3) non BC with one } \\
\text { RF }\end{array}$ & $\begin{array}{l}\text { Urban safety-net } \\
\text { hospital, } 7 / 2015- \\
7 / 2017\end{array}$ & $n=1752$ & $\begin{array}{l}\text { Acceptance of test: } \\
\text { BC-RF+ > BC+RF- } \\
\text { > BC+RF+ Overall } \\
\text { HCV Ab-positive: } \\
3.4 \% \text { BC+ RF+: } \\
12.5 \% \text { BC- RF+: } \\
4.9 \% \text { BC+ RF-: } \\
1.3 \% \text {-higher in US } \\
\text { born patients }\end{array}$ \\
\hline Hirode (2019) & Abstract & Observational & $\begin{array}{l}\text { Outpatient } \\
\text { endoscopy-based } \\
\text { patient navigator } \\
\text { model for adults } \\
\text { undergoing } \\
\text { endoscopy }\end{array}$ & $\begin{array}{l}\text { Urban safety-net } \\
\text { hospital, } 7 / 2015- \\
9 / 2018\end{array}$ & $n=3624$ & $\begin{array}{l}\text { Eligible for HCV } \\
\text { screening }(69.2 \%) \\
\text { based on: BC: } \\
89.8 \% \text { At least } 1 \\
\text { HCV RF: } 30.4 \% \\
\text { Eligible patients } \\
\text { tested increased } \\
\text { from } 50.8 \% \text { to } \\
77.9 \%\end{array}$ \\
\hline Wong (2017) & Abstract & $\begin{array}{l}\text { Prospective } \\
\text { cohort }\end{array}$ & $\begin{array}{l}\text { Adults undergoing } \\
\text { outpatient } \\
\text { endoscopy }\end{array}$ & $\begin{array}{l}\text { Underserved } \\
\text { safety-net } \\
\text { hospital, 7/2015- } \\
6 / 2016\end{array}$ & $n=1125$ & $\begin{array}{l}\text { Trend towards } \\
\text { lower HCV test } \\
\text { acceptance among } \\
\text { BC (odds ratio } \\
0.39,95 \% \\
\text { confidence } \\
\text { interval: } 0.13- \\
1.14 \text { ) High risk } \\
\text { (including BC): } \\
66.5 \% \text { HCV test } \\
\text { accepted: } 85.4 \%\end{array}$ \\
\hline
\end{tabular}


Tsay C.J. et al: Birth cohort screening for HCV

Table 1. (continued)

\begin{tabular}{|c|c|c|c|c|c|c|}
\hline Study & Type & Design & Population & Setting & Sample size & Outcomes \\
\hline \multicolumn{7}{|l|}{ ED } \\
\hline Hyun (2017) & Abstract & $\begin{array}{l}\text { Prospective } \\
\text { cohort }\end{array}$ & $\begin{array}{l}\text { Adults born } \\
\text { between 1945- } \\
1965 \text { presenting to } \\
\text { ED using } \\
\text { streamlined EHR } \\
\text { ordering with } \\
\text { patient navigators } \\
\text { contacting } \\
\text { individuals with } \\
\text { confirmed infection } \\
\text { by automated } \\
\text { certified letters and } \\
\text { phone calls for } \\
\text { linkage to care }\end{array}$ & $\begin{array}{l}\text { ED of community } \\
\text { hospital, } 2 / 2016- \\
1 / 2017\end{array}$ & $n=12,617$ & $\begin{array}{l}\text { HCV tested: } 40.2 \% \\
\text { (5069/12617) HCV } \\
\text { Ab-positive: } \\
3.99 \% \text { (202/5069) } \\
\text { HCV RNA PCR- } \\
\text { positive: } 1.32 \% \\
\text { (67/5069) Linkage } \\
\text { of care rate } 37.3 \% \\
\text { in } 6 \text { month period } \\
\text { patient navigation; } \\
\text { awareness of } \\
\text { infection in } \\
\text { chronically infected } \\
\text { but not engaged in } \\
\text { care: } 38.8 \% \text { ( } 26 / \\
67)\end{array}$ \\
\hline Minhas (2019) & Abstract & $\begin{array}{l}\text { Retrospective } \\
\text { cohort }\end{array}$ & $\begin{array}{l}\text { Adults born between } \\
1945-1965 \\
\text { presenting to ED } \\
\text { with testing } \\
\text { conducted on an } \\
\text { opt-out basis ( } 2 / \\
2017-11 / 2017 \text { ) } \\
\text { then when } \\
\text { notification was no } \\
\text { longer required on } \\
\text { all-comers (11/ } \\
2017-1 / 2018 \text { ) with } \\
\text { referral to affiliated } \\
\text { hepatology clinic }\end{array}$ & $\begin{array}{l}\text { ED of urban } \\
\text { hospital, } 2 / 2017- \\
1 / 2018\end{array}$ & $n=1525$ & $\begin{array}{l}\text { HCV Ab-positive: } \\
\text { 15.5\% (237/1525) } \\
\text { HCV RNA PCR- } \\
\text { positive: } 67.9 \% \\
\text { (161/237) Referral } \\
\text { to hepatology: } \\
75 \%(121 / 161)\end{array}$ \\
\hline Allison (2016) & $\begin{array}{l}\text { Full- } \\
\text { text }\end{array}$ & Cross sectional & $\begin{array}{l}\text { Adults born between } \\
1945-1965 \\
\text { presenting to ED } \\
\text { were provided study } \\
\text { information sheet } \\
\text { and CDC } \\
\text { information sheet in } \\
\text { HCV testing in baby } \\
\text { boomers, then } \\
\text { participated in } \\
\text { researcher- } \\
\text { administered } \\
\text { questionnaire, those } \\
\text { with positive HCV Ab } \\
\text { were referred to } \\
\text { clinic, non- } \\
\text { attendance resulted } \\
\text { in telephone call }\end{array}$ & $\begin{array}{l}\text { ED of a large urban } \\
\text { academic hospital } \\
\text { (Bellevue, WA) in a } \\
\text { state where birth } \\
\text { cohort is mandated } \\
\text { by law in all non- } \\
\text { ED healthcare } \\
\text { settings, 10/2014- } \\
7 / 2015\end{array}$ & $n=915$ & $\begin{array}{l}\text { Structured } \\
\text { interview: } 46.7 \% \\
\text { (427/915) HCV } \\
\text { tested: } 90.0 \% \\
\text { (383/427) HCV } \\
\text { Ab-positive: } 7.4 \%\end{array}$ \\
\hline
\end{tabular}


Tsay C.J. et al: Birth cohort screening for HCV

Table 1. (continued)

\begin{tabular}{|c|c|c|c|c|c|c|}
\hline Study & Type & Design & Population & Setting & Sample size & Outcomes \\
\hline $\begin{array}{l}\text { Cornett } \\
(2018)\end{array}$ & $\begin{array}{l}\text { Full- } \\
\text { text }\end{array}$ & $\begin{array}{l}\text { Retrospective } \\
\text { cohort }\end{array}$ & $\begin{array}{l}\text { Adults born } \\
\text { between } 1945- \\
1965 \text { presenting to } \\
\text { ED with an opt-out } \\
\text { test order } \\
\text { generated by the } \\
\text { EHR seen between } \\
11 \text { am-7pm and } \\
\text { given handout } \\
\text { explaining rationale } \\
\text { with plan for } \\
\text { contacting patients } \\
\text { with results }\end{array}$ & $\begin{array}{l}\text { ED of small urban/ } \\
\text { suburban area } \\
\text { tertiary care } \\
\text { academic hospital, } \\
6 / 2016-12 / 2016\end{array}$ & $n=3046$ & $\begin{array}{l}\text { HCV tested: } \\
96.1 \%(2928 / \\
3046) \text { HCV Ab- } \\
\text { positive: } 6.6 \% \\
\text { (192/2928) HCV } \\
\text { RNA PCR-positive: } \\
43 \%(71 / 167)\end{array}$ \\
\hline $\begin{array}{l}\text { Galbraith } \\
(2015)\end{array}$ & $\begin{array}{l}\text { Full- } \\
\text { text }\end{array}$ & Cross sectional & $\begin{array}{l}\text { Adults born } \\
\text { between 1945- } \\
1965 \text { presenting to } \\
\text { ED with an opt-out } \\
\text { as part of standard } \\
\text { clinical care, } \\
\text { therefore no } \\
\text { informed consent } \\
\text { was required with } \\
\text { ED nurses } \\
\text { screening using } \\
\text { questionnaire } \\
\text { embedded in the } \\
\text { EHR with } \\
\text { informational } \\
\text { packet given to } \\
\text { HCV-positive } \\
\text { individuals and } \\
\text { linkage to care } \\
\text { specialist } \\
\text { information with } \\
\text { coordinator arrange } \\
\text { follow-up and } \\
\text { phone call follow- } \\
\text { up }\end{array}$ & $\begin{array}{l}\text { ED of a large } \\
\text { academic urban } \\
\text { hospital (UAB) in a } \\
\text { socioeconomically } \\
\text { disadvantaged } \\
\text { population, } 9 / \\
2013-11 / 2013\end{array}$ & $n=3170$ & $\begin{array}{l}\text { Unaware of HCV } \\
\text { status: } 73.2 \% \\
\text { (2323/3170) } \\
\text { Opted out: } 12.7 \% \\
\text { (289/2323) } \\
\text { Automated test } \\
\text { order: } 87.3 \% \\
\text { (1988/2323) HCV } \\
\text { tested: } 76.9 \% \\
\text { (1529/1988) HCV } \\
\text { Ab-positive: } \\
\text { 11.1\% (170/1529) } \\
\text { HCV RNA tested: } \\
88.2 \%(150 / 170) \\
\text { HCV RNA PCR- } \\
\text { positive: } 68.0 \% \\
\text { (102/150) }\end{array}$ \\
\hline Hsieh (2016) & $\begin{array}{l}\text { Full- } \\
\text { text }\end{array}$ & $\begin{array}{l}\text { Retrospective } \\
\text { cohort identity } \\
\text { unlinked } \\
\text { seroprevalence }\end{array}$ & $\begin{array}{l}\text { Adults aged }>17 \\
\text { years-old } \\
\text { presenting to a } \\
\text { large academic } \\
\text { urban hospital ED } \\
\text { with excess blood } \\
\text { specimen }\end{array}$ & $\begin{array}{l}\text { ED of a large } \\
\text { academic urban } \\
\text { hospital (JHU) in a } \\
\text { socioeconomically } \\
\text { disadvantaged } \\
\text { population, 6/ } \\
2013-8 / 2013\end{array}$ & $\mathrm{n}=4713$ & $\begin{array}{l}\text { HCV Ab-positive: } \\
\text { 13.8\% (652/4713) } \\
\text { Undocumented } \\
\text { HCV infection: } \\
31.3 \%(204 / 652) \\
\text { Diagnosed by BC: } \\
\text { 48.5\% (99/204) } \\
\text { Diagnosed by RF: } \\
26.5 \%(54 / 204)\end{array}$ \\
\hline
\end{tabular}


Tsay C.J. et al: Birth cohort screening for HCV

Table 1. (continued)

\begin{tabular}{|c|c|c|c|c|c|c|}
\hline Study & Type & Design & Population & Setting & Sample size & Outcomes \\
\hline Lyons (2016) & $\begin{array}{l}\text { Full- } \\
\text { text }\end{array}$ & $\begin{array}{l}\text { Cross sectional } \\
\text { seroprevalence }\end{array}$ & $\begin{array}{l}\text { Adults between the } \\
\text { ages of } 18-64 \\
\text { presenting to the } \\
\text { ED were consented } \\
\text { to a "study of } \\
\text { disease of public } \\
\text { health importance" } \\
\text { and given } \\
\text { compensation, risk } \\
\text { factors assessed } \\
\text { via health } \\
\text { questionnaires, } \\
\text { deidentified data }\end{array}$ & $\begin{array}{l}\text { ED of urban } \\
\text { academic hospital, } \\
1 / 2008-12 / 2009\end{array}$ & $n=1034$ & $\begin{array}{l}\text { HCV tested: } 89 \% \\
\text { (924/1034) HCV } \\
\text { Ab-positive: } 14 \% \\
\text { (128/924) HCV } \\
\text { RNA PCR-positive: } \\
81 \% \text { (103/128) } \\
\text { Birth cohort only } \\
\text { testing would have } \\
\text { missed } 28 \% \text { (36/ } \\
\text { 128) HCV Ab- } \\
\text { positive, } 25 \% \text { (26/ } \\
\text { 105) HCV RNA- } \\
\text { positive } \\
\text { Awareness of prior } \\
\text { diagnosis: } 32 \% \\
\text { (41/128) }\end{array}$ \\
\hline $\begin{array}{l}\text { Schechter- } \\
\text { Perkins (2018) }\end{array}$ & $\begin{array}{l}\text { Full- } \\
\text { text }\end{array}$ & Descriptive & $\begin{array}{l}\text { Individuals }>13 \\
\text { years-old of age } \\
\text { presenting to the } \\
\text { ED undergoing } \\
\text { phlebotomy for } \\
\text { clinical purposes, } \\
\text { non-targeted, opt- } \\
\text { out screening with } \\
\text { a best practice } \\
\text { advisory alert with } \\
\text { navigators to } \\
\text { facilitate linkage to } \\
\text { care for those with } \\
\text { positive RNA }\end{array}$ & $\begin{array}{l}\text { ED of urban } \\
\text { academic hospital } \\
(B M C), 11 / 2016- \\
1 / 2017\end{array}$ & $n=3936$ & $\begin{array}{l}\text { HCV tested: } 3808 \\
\text { HCV Ab-positive: } \\
\text { 13.2\% (504/3808) } \\
\text { HCV RNA PCR- } \\
\text { positive: } 59.2 \% \\
\text { (292/493) Outside } \\
\text { BC with active } \\
\text { infection: } 54 \% \\
\text { (115) Linkage to } \\
\text { care: } 76.4 \% \text { ( } 223 \text { ) } \\
\text { Appointments } \\
\text { scheduled: } 38 \% \\
\text { (102) Attended } \\
\text { LTC visit: } 22.5 \% \\
\text { (66) }\end{array}$ \\
\hline White (2016) & $\begin{array}{l}\text { Full- } \\
\text { text }\end{array}$ & $\begin{array}{l}\text { Retrospective } \\
\text { cohort }\end{array}$ & $\begin{array}{l}\text { Adults born } \\
\text { between } 1945- \\
1965 \text { or reporting } \\
\text { any use of injection } \\
\text { drugs who were not } \\
\text { known to be HCV- } \\
\text { positive to triage } \\
\text { nursing, EMR, with } \\
\text { opt-out testing } \\
\text { requiring consent } \\
\text { with physicians } \\
\text { able to choose } \\
\text { testing at clinical } \\
\text { discretion } \\
\text { (diagnostic) with } \\
\text { informational } \\
\text { packets sent to } \\
\text { HCV-positive } \\
\text { patients with } \\
\text { referral to primary } \\
\text { care which could } \\
\text { then be canceled if } \\
\text { RNA test was } \\
\text { negative }\end{array}$ & $\begin{array}{l}\text { ED of Highland } \\
\text { Hospital-Alameda } \\
\text { Health System, } \\
\text { single-center } \\
\text { urban ED, 4/2014- } \\
10 / 2014\end{array}$ & $n=26639$ & $\begin{array}{l}\text { HCV tested: } 9.7 \% \\
\text { (2581/26,639) } \\
\text { HCV Ab-positive: } \\
\text { 10.3\% (267/2581) } \\
\text { Screening Ab test: } \\
\text { 79\% (2028/2581) } \\
\text { Diagnostic Ab test: } \\
21 \% \text { (553/2581) } \\
\text { Screening HCV Ab- } \\
\text { positive: } 9.1 \% \\
\text { (185/2028) } \\
\text { Diagnostic HCV } \\
\text { Ab-positive: } \\
\text { 14.8\% (82/553) }\end{array}$ \\
\hline
\end{tabular}


Tsay C.J. et al: Birth cohort screening for HCV

Table 1. (continued)

\begin{tabular}{|c|c|c|c|c|c|c|}
\hline Study & Type & Design & Population & Setting & Sample size & Outcomes \\
\hline \multicolumn{7}{|c|}{ Non-physician providers } \\
\hline $\begin{array}{l}\text { Shelgrove } \\
\text { (2018) }\end{array}$ & Abstract & $\begin{array}{l}\text { Prospective } \\
\text { cohort }\end{array}$ & $\begin{array}{l}\text { Patients born } \\
\text { between 1945- } \\
1965 \text { in Yuba, } \\
\text { Sutter, Colusa } \\
\text { Counties. Also } \\
\text { included patients } \\
\text { ages } 18-64 \text { years- } \\
\text { old in Butte, Glenn, } \\
\text { Tehama Counties. } \\
\text { Patients with high } \\
\text { risk factors. } \\
\text { Followed HCV Ab } \\
\text { testing with reflex } \\
\text { HCV RNA testing by } \\
\text { PCR }\end{array}$ & $\begin{array}{l}\text { Ampla Health (a } \\
\text { Federally Qualified } \\
\text { Health Center) } \\
\text { offering medical, } \\
\text { dental, mental } \\
\text { health, specialty } \\
\text { healthcare } \\
\text { services in } \\
\text { Northern } \\
\text { California, } \\
\text { screening from 8/ } \\
\text { 2017-4/2018 }\end{array}$ & $n=5481$ & $\begin{array}{l}\text { Detected HCV Ab } \\
\text { seropositivity in } \\
7.5 \%(410 / 5481) \text {. } \\
45 \% \text { (183/410) } \\
\text { RNA-positive. } \\
\text { Overall, } 3.3 \% \\
\text { RNA-positive } \\
\text { which averages to } \\
20 \text { HCV diagnosed } \\
\text { patients/month } \\
\text { HCV Ab-positive: } \\
7.5 \%(410 / 5481) \\
\text { HCV RNA-positive: } \\
45 \% \text { (183/410) } \\
\text { HCV RNA-positive } \\
\text { overall: } 3.3 \% \\
\text { (183/5481), } \\
\text { average of } 20 \text { HCV } \\
\text { diagnosed patients } \\
\text { /month RNA- } \\
\text { positive HCV reflex } \\
\text { testing lead to } \\
\text { timely diagnosis } \\
\text { and LTC Patients } \\
\text { attending follow- } \\
\text { up appointment: } \\
92 \% \text { (168/183) }\end{array}$ \\
\hline Travis (2018) & Abstract & $\begin{array}{l}\text { Retrospective } \\
\text { chart review }\end{array}$ & $\begin{array}{l}\text { Patients born } \\
\text { between } 1945- \\
1965\end{array}$ & $\begin{array}{l}\text { Emory Midtown } \\
\text { University Primary } \\
\text { Care Clinic, 12/1/ } \\
2015-5 / 1 / 2018 . \\
\text { Implemented } \\
\text { "HCV screen" on } \\
\text { patient intake form } \\
\text { on } 12 / 1 / 2016 .\end{array}$ & $n=10,803$ & $\begin{array}{l}\text { HCV screening } \\
\text { rates increased } \\
\text { after intervention. } \\
\text { Before } \\
\text { intervention was } \\
5 \%(232 / 4336) \text {. } \\
\text { After intervention } \\
\text { screening rates } \\
\text { went to } 18 \% \text { ( } 765 / \\
3498) \text { in } 2016- \\
2017 \text { and } 23 \% \\
(880 / 2969) \text { in } \\
2017-2018 \text {. }\end{array}$ \\
\hline Dong (2017) & $\begin{array}{l}\text { Full- } \\
\text { text }\end{array}$ & $\begin{array}{l}\text { Prospective } \\
\text { cohort }\end{array}$ & $\begin{array}{l}\text { Patients in } \\
\text { California in BBBC, } \\
\text { high risk patients } \\
\text { with hx of IVDU, } \\
\text { crack cocaine or } \\
\text { methamphetamine } \\
\text { use. }\end{array}$ & $\begin{array}{l}\text { Community } \\
\text { pharmacy-based } \\
\text { HCV-Ab POC } \\
\text { screening program } \\
\text { in California in } \\
\text { collaboration with } \\
\text { the local public } \\
\text { health } \\
\text { department. } 3 \\
\text { month pilot, } 6 \\
\text { community } \\
\text { pharmacists. }\end{array}$ & $n=83$ & $\begin{array}{l}\text { HCV-Ab rapid POC- } \\
\text { positive: } 1.2 \%(1 / \\
83)\end{array}$ \\
\hline
\end{tabular}

Abbreviations: Ab, antibody; BBBC, baby boomer birth cohort; BC, birth cohort; BPAs, best practice alerts; BMC, Boston Medical Center; CDC, Centers for Disease Control; ED, emergency department; EHR, electronic health record; EMR, electronic medical record; HCV, hepatitis C virus; IVDU, intravenous drug use; JHU, Johns Hopkins University; LTC, linkage to care; PCP, Primary care physician; PDSA, plan, do, study, act; POC, point of care; RF, risk factor; UAB, University of Alabama-Birmingham.

widely from increases of 1.8 - to 15.8 -fold. ${ }^{32,33}$ Two studies examined the impact of educational intervention for outpatient primary care providers versus EMR alerts alone, and found an increase in screening rates as high as $45 \%$ to $55 \%$ at 3 months after a single education session. ${ }^{28,34}$ While EMR alerts represent an easily adapted, systems-based intervention to increase birth cohort screening, current studies have been limited to largely small single-center interventions in 
unique clinical settings, with limited information on downstream outcomes within the care cascade, including RNA confirmation, linkage to care, and HCV treatment.

One of the few multicenter studies examining outpatient screening interventions was reported by Turner et al. ${ }^{35}$ who evaluated the feasibility and impact of the Reach, Effectiveness, Adoption, Implementation, Maintenance model in a state-funded program to implement birth cohort testing in five federally qualified healthcare centers and one family medicine residency program. Within a cohort of 27,700 baby boomers born 1945-1965, 13,334 (48.1\%) successfully underwent HCV Ab testing, 695 were HCV Ab-positive (5.2\%), 349 were HCV RNA-positive $(2.6 \%), 82$ initiated DAA therapy, 74 completed DAA therapy, and 70 achieved a sustained virologic response (SVR). In this grant funded intervention study involving multilevel practice engagement strategies, patient navigation, standardized $\mathrm{HCV} A \mathrm{~b}$ and reflex HCV RNA testing, and access to free DAA therapy via prescription assistance programs, HCV birth cohort screening increased from $0.8 \%$ to $48.1 \%$ between 2014 and 2018 . This study additionally identified multiple barriers and challenges to birth screening interventions, significant site-level variability in performance, and the central importance of best practice alerts (BPAs), reflex RNA testing, access to specialty consultation via telemedicine, and role of local champions.

\section{Inpatient}

The inpatient setting provides a unique place for birth cohort screening. Multiple studies have demonstrated that inpatient screening is effective in identifying new cases of HCV but may not translate to effective linkage to care or treatment, and is limited by factors such as socioeconomic status, racial disparities, and lack of insurance. ${ }^{36,37}$ Two studies examined the effect of the 2014 New York state HCV screening law within large academic hospitals and showed that despite a significant increase in screening rates, 8 to $39 \%$ and 53 to $84 \%$, respectively, very few patients were linked to care or received DAA treatment, with an overall decrease in treatment initiation during the period of observation. ${ }^{38}$ The challenges of inpatient screening may be driven by variable access to reflex RNA testing, provider-led results reporting and education, and outpatient follow-up after hospital discharge, and underscores the need for additional research to clarify evidence-based strategies to augment linkage to care.

\section{Direct patient solicitation}

Multiple strategies targeted at direct patient contact have been explored to increase screening rates, including direct mail campaigns, with letters containing educational material and blood test request forms distributed to birth cohort patients identified via EMR. ${ }^{39,40}$ One study compared liveperson recruitment through either phone call, direct mail, or electronic health record prompt at three study sites and found that all three methods were significantly limited by requirement for substantial administrative and staffing resources beyond existing clinic infrastructure. One randomized controlled trial assigned patients to one of three independent implementation strategies: repeated mailings, BPA through electronic health record, or direct phone solicitation. ${ }^{41}$ Compared to controls, all three methods were associated with increased screening, with repeat mailings, BPA, and direct phone solicitation resulting in 8 times, 2.6 times, and 5 times control rates, respectively, suggesting that direct patient contact may represent a valuable, complementary tool to augment birth cohort screening efforts.

\section{Colonoscopy}

Patients undergoing routine colonoscopy for colorectal cancer screening overlap with patients born 1945-1965 (age 54-74 years as of 2019). This concordance of age makes point-ofcare testing (POCT) in the colonoscopy suite a unique setting for HCV screening. Abu-Heija et al. ${ }^{42,43}$ reported the results of a retrospective cohort study of a predominantly African American population undergoing colonoscopy in an urban openaccess colonoscopy suite, and identified an increase in birth cohort HCV testing from $31 \%$ to $40.3 \%$ between 2014-2017, high rates of HCV Ab positivity ( 31.5 to $42.9 \%$ ), and higher likelihood of screening among patients referred from university-affiliated clinicians. Another study performed in USA veterans examined the impact of a same-day HCV testing during colonoscopy which involved registered nurse pre-screening and phone consent for HCV Ab testing in birth cohort patients 1 day prior to scheduled colonoscopy, followed by laboratory draw at the time of intravenous line placement for colonoscopy; this intervention resulted in an $85 \% \mathrm{HCV}$ Ab testing rate in this setting. ${ }^{44}$ Other studies have reported slightly lower rates for HCV Ab testing among patients undergoing colonoscopy targeted on the basis of risk factors identified by patient survey. ${ }^{45,46}$

\section{Endoscopy}

Outside the specific context of colorectal cancer screening, the endoscopy suite broadly provides an opportunity for HCV screening by gastroenterologists who are uniquely positioned to offer real-time $A b$ testing, results reporting, patient education, and linkage to care including DAA treatment. Few studies have examined prospective interventions in the endoscopy suite incorporating both birth cohort- and risk factor-based testing. One urban safety-net hospital in California conducted a series of studies ${ }^{47,48}$ to examine HCV screening practices in the endoscopy suite setting, and identified lower test acceptance among birth cohort versus nonbirth cohort populations (odds ratio: $0.39,95 \%$ confidence interval: $0.13-1.14, p=0.09)^{48}$ and $82.5 \%$ versus $93.9 \%$ $(p=0.004) .{ }^{47}$ Integration of a pre-screening tool and a patient navigator tool in the outpatient endoscopy suite resulted in an overall increase in eligible patients who were tested (50.8\% to $77.9 \%$ ); although, the authors identified a persistent gap in HCV testing in positive risk factor groups, as well as significant challenges in achieving patient acceptance and engagement. ${ }^{49}$

\section{$E D$}

Historic studies of HCV screening in ED populations prior to implementation of birth cohort screening guidelines revealed a higher prevalence than in the general population, with rates ranging from $4 \%$ in Michigan to $18 \%$ in Baltimore. ${ }^{50-55}$ Although our review focused specifically on patients within the 1945-1965 year-range, some studies have revealed that testing restricted to the birth cohort alone may miss identification of up to $28 \%$ of HCV Ab-positive patients seen in the ED setting. ${ }^{56}$ Recent reports have additionally identified high levels of patient acceptance of HCV testing in the ED setting 
Tsay C.J. et al: Birth cohort screening for HCV

( $90 \%$ of those completed a structured interview), but sobering low rates of linkage to care following testing among $A b$ positive patients. ${ }^{54,57}$ A large CDC-funded study conducted in an urban academic ED center in Alabama demonstrated similarly high patient acceptance of HCV testing (88\%), high HCV Ab positivity (11\%), and high HCV RNA testing of Ab positive patients $(88 \%) .{ }^{58}$ However, among patients confirmed with chronic HCV infection (68\% RNA positive among Ab-positive group), only $54 \%$ attended a hepatology clinic appointment following discharge despite automated phone calls and a care coordinator focused on linkage to care. Another study examining HCV testing of birth cohort versus all adults in an urban ED in California revealed higher HCV Ab positivity in birth cohort versus all adults (13.7\% vs. $10.3 \%)$, limited HCV RNA confirmation testing (67\%), similar proportion of HCV RNA-positive patients confirmed with chronic infection (70\%), and poor linkage to care, with only $24 \%$ of RNA positive individuals attending a postdischarge clinic appointment. ${ }^{59} \mathrm{~A}$ recent study in a large urban academic ED in Boston similarly revealed high HCV Ab positivity (13.2\%) and poor attendance at postdischarge clinic appointment (22.5\%) among HCV RNA-positive patients. ${ }^{60}$ These findings underscore the high yield of targeted HCV screening in the ED context, as well as the need for innovative strategies to augment linkage to care to promote more effective patient navigation.

\section{Non-physician providers}

Non-physician clinicians including nurses, care coordinators, patient navigators, pharmacists, and advanced practice providers, such as physician assistants, nurse practitioners, and advance practice registered nurses, play a central role in all aspects of HCV screening, care navigation, and treatment, and have featured prominently in nearly all interventional studies targeting birth cohort screening. However, few studies have examined the specific roles of non-physician providers. Shelgrove et al. ${ }^{61}$ highlighted the importance of care coordinators and clinic managers in the context of a federally qualified healthcare centers in California, with a focus on augmenting linkage to care. Among a cohort of patients screened for HCV, 7.5\% were HCV Ab-positive (410/5481), of whom $45 \%$ were HCV RNA-positive with reflex testing $(183 / 410)$, and $92 \%(164 / 183)$ successfully attended an appointment with either a primary care physician or specialist following diagnosis of chronic HCV infection; these findings contrast sharply with the comparatively low rates of linkage to care $(22.5-37.3 \%)$ reported in other studies, such as the CDC Hepatitis Testing and Linkage to Care initiative. ${ }^{60,62,63}$

Utilizing medical assistants to identify eligible patients for $\mathrm{HCV}$ screening by means of printed patient intake forms within an outpatient primary care clinic resulted in increased testing rates, from $5 \%$ up to $23 \% .{ }^{64}$ Another research group reported the novel use of clinical pharmacists to offer pointof-care HCV Ab testing to high risk and birth cohort patients seen at a community-based pharmacy. ${ }^{65}$ It is likely that a combination of interventions using physician and non-physician providers across practice settings will be necessary to meaningfully expand HCV screening in both birth cohort and high-risk populations.

\section{Birth cohort screening in USA veterans}

The USA Veterans Health Administration (VHA) has represented a national leader in efforts to screen and manage HCV using systems-based approaches. One early retrospective cohort study from 2011 in the Atlanta Veterans Affairs Medical Center described that over half of birth cohort veterans in care had been tested for HCV, and those born in the birth cohort were 6 times more likely to have a positive HCV Ab test and 3 times more likely to have chronic HCV compared to non-birth cohort veterans. ${ }^{66}$ A 2016 report examined HCV testing practices within the national VHA system among 4.2 million birth cohort veterans receiving care between 2000-2013, and confirmed that $51 \%$ had undergone HCV testing; significant local and regional variabilities in testing practices (7-83\%) were identified, and up to $20 \%$ of birth cohort veterans with FIB4 scores suggestive of advanced fibrosis or cirrhosis had not received $\mathrm{HCV}$ testing. ${ }^{67}$

In the context of national efforts by Veterans Affairs' leadership to adopt birth cohort HCV screening recommendations, HCV Ab testing in birth cohort veterans had increased to nearly $70 \%$ as of $2017 .{ }^{67-69}$ The VHA has employed a multifaceted, integrated approach, including the formation of regional HCV innovation teams focused on increasing birth cohort testing, adoption of a national HCV testing electronic clinical reminder, establishing HCV testing as a regional and national VA quality performance metric, and publishing quarterly reporting of $\mathrm{HCV}$ birth cohort testing rates at site, regional, and national levels to enhance transparency and accountability. ${ }^{68}$ Many of these strategies may potentially be applicable to large non-federal health systems but requires high-level engagement by leadership and institutional commitment to achieving similar levels of success.

\section{POCT and rapid detecting tests (RDTs)}

The CDC and USPSTF guidelines recommend that HCV Ab testing should be performed as a screening test of choice, and positive results should be reflexed to HCV RNA test by PCR or nucleic acid testing. ${ }^{70,71}$ The gold standard test for anti-HCV identification has been the enzyme immunoassay, which takes several days to weeks to process a result, and has significant laboratory requirements, including high-cost equipment, trained technicians, continuous supply of electricity and high facility cost. In contrast, newer rapid point-of-care immunoassays can provide results in as little as 20-40 m. The OraQuick test represents the most widely used POCT in the USA, approved by the Federal Drug Administration in 2010, and can detect HCV Ab in saliva or blood. ${ }^{72}$ One meta-analysis reported a pooled sensitivity of $98 \%$ ( $95 \%$ confidence interval: $98-100 \%)$ and specificity of $100 \%$ (95\% confidence interval: $100-110 \%$ ) for HCV Ab rapid diagnostic test compared to the enzyme immunoassay reference standard. Another pooled analysis of eight studies demonstrated that OraQuick ADVANCE was associated with a sensitivity of $98 \%$ compared to $88 \%$ with other oral assays. ${ }^{73}$ RDTs are often faster than POCTs but require specialized equipment and specially trained personnel, are limited to HCV Ab detection (unable to detect HCV RNA), and associated with lower diagnostic performance than POCTs. ${ }^{74}$ Further studies to define optimal use of POCTs and RDTs may be helpful in identifying their appropriate role in HCV screening efforts. 


\section{Future directions}

Despite major advances in antiviral therapy for chronic HCV infection since 2014, persistent deficits in the HCV care cascade within the USA threaten to limit the capacity to achieve meaningful changes in the burden of chronic infection and downstream clinical outcomes, as well as ambitious targets for HCV elimination by the WHO and USA Department of Health and Human Services. Although progress has been made within each step of the cascade, including screening (HCV Ab), confirmation (HCV RNA), linkage to care, and treatment, identification of uninfected patients represents the critical rate-limiting step. Additional challenges to achieving $\mathrm{HCV}$ elimination include ongoing late relapse and reinfection among patients who achieve sustained virologic response.

Since implementation of new recommendations for onetime HCV Ab testing in all USA adults born $1945-1965$ by the CDC and USPSTF, birth cohort screening has provided a central focus for health system, state, and national level efforts to increase the diagnosis of chronic HCV. A multifaceted integrative approach to screening which integrates clinical education, clinical decision support, reflex HCV RNA testing, and incorporation of non-physician providers have been proven to be successful in increasing HCV screening. However, multiple studies have confirmed that overall screening rates within the USA outside the VHA remain low, despite success within individual centers and health systems. Based on the available literature, no single strategy appears to be easily applicable across clinical settings.

Our review underscores the need for the following steps: 1) patient and provider education to address a persistent deficit in knowledge, regarding both HCV risk factors as well as national screening recommendations; 2) engagement of health systems to incorporate standardized tools, such as reflex HCV RNA testing and EMR alerts to prompt clinicians to pursue HCV testing across the inpatient, emergency department, outpatient clinic, pharmacy, and endoscopy center settings; and 3) strategic use of novel diagnostic tests (e.g. POCT/RDT) and emerging technologies (e.g. text alerts) in appropriate clinical settings. Significant resources may be required to fully support the multidisciplinary programs required to meaningfully impact broader efforts for screening, linkage to care, and treatment.

Furthermore, emerging data suggest that birth cohort screening will be inadequate to identify the growing cohort of non-birth cohort adults with chronic $\mathrm{HCV}$, including a rising population of young adults recently infected with HCV in the context of substance use and the opiate epidemic. Recent NHANES reports suggest an overall decrease in chronic HCV prevalence from $1.32 \%$ to $0.80 \%$ between $1999-2004$ and 2011-2016; although, an estimated 1.90 million USA adults continued to have viremic HCV, of whom only $49.8 \%$ were reportedly aware of their infection. ${ }^{75}$ An updated report which combined NHANES data with high-risk populations excluded by NHANES (prisoners, unsheltered homeless persons, active-duty military personnel, nursing home residents) estimated a prevalence of 2.4 million HCV RNA-positive persons. ${ }^{2}$ Expansion from birth cohort to universal screening of all USA adults may identify up to an estimated $28 \%$ of HCV-infected individuals who would be missed by birth cohort ${ }^{55-60}$ or risk factor-based screening strategies. ${ }^{76}$ In addition, economic models have demonstrated that a universal screening strategy in USA adults is more cost effective than a birth cohort screening strategy in populations with a $\mathrm{HCV}$ prevalence $>0.07 \%$ among non-birth cohort adults. ${ }^{77}$ This emerging evidence of increasing HCV incidence in younger adults ${ }^{78}$ and resulting gap in identification of HCV-infected persons have prompted reconsideration of USA HCV screening guidelines.

In 2019, several organizations have publicly called for expansion of HCV screening to a universal approach to offer one-time HCV Ab testing to all USA adults age 18-79 years or age 18 years and older, including draft statements by the USPSTF (August 2019) ${ }^{79}$ and CDC (October 2019), ${ }^{80}$ as well as updated language within the HCV guidance document of the Infectious Diseases Society of America and American Association for the Study of Liver Diseases (November 2019). ${ }^{81}$ In the context of these emerging changes in national screening recommendations, significant additional research is needed to support evidence-based recommendations on population and system-level HCV screening strategies. Lessons learned from early experiences with birth cohort screening studies may help inform future research and public health efforts at implementation of future universal screening initiatives.

\section{Funding}

None to declare.

\section{Conflict of interest}

The authors have no conflict of interests related to this publication.

\section{Author contributions}

Study concept and design, and critical revision of the manuscript for important intellectual content (JKL), acquisition of data (CJT), analysis and interpretation of data and drafting of the manuscript (JKL and CJT).

\section{References}

[1] Ly KN, Hughes EM, Jiles RB, Holmberg SD. Rising mortality associated with hepatitis C virus in the United States, 2003-2013. Clin Infect Dis 2016;62: 1287-1288. doi: 10.1093/cid/ciw111.

[2] Hofmeister MG, Rosenthal EM, Barker LK, Rosenberg ES, Barranco MA, Hall EW, et al. Estimating prevalence of hepatitis $C$ virus infection in the United States, 2013-2016. Hepatology 2019;69:1020-1031. doi: 10.1002/hep.30297.

[3] Smith BD, Morgan RL, Beckett GA, Falck-Ytter Y, Holtzman D, Ward JW. Hepatitis $C$ virus testing of persons born during 1945-1965: recommendations from the Centers for Disease Control and Prevention. Ann Intern Med 2012; 157:817-822. doi: 10.7326/0003-4819-157-9-201211060-00529.

[4] Tomaszewski KJ, Deniz B, Tomanovich P, Graham CS. Comparison of current US risk strategy to screen for hepatitis $C$ virus with a hypothetical targeted birth cohort strategy. Am J Public Health 2012;102:e101-e106. doi: 10. 2105/AJPH.2011.300488.

[5] Smith BD, Morgan RL, Beckett GA, Falck-Ytter Y, Holtzman D, Teo CG, et al. Recommendations for the identification of chronic hepatitis $C$ virus infection among persons born during 1945-1965. MMWR Recomm Rep 2012;61:1-32.

[6] Chou R, Cottrell EB, Wasson N, Rahman B, Guise JM. Screening for hepatitis C virus infection in adults: a systematic review for the U.S. Preventive Services Task Force. Ann Intern Med 2013;158:101-108. doi: 10.7326/0003-4819158-2-201301150-00574.

[7] Moyer VA. Screening for hepatitis $C$ virus infection in adults: U.S. Preventive Services Task Force recommendation statement. Ann Intern Med 2013;159: 349-357. doi: 10.7326/0003-4819-159-5-201309030-00672.

[8] Patel EU, Mehta SH, Boon D, Quinn TC, Thomas DL, Tobian AAR. Limited coverage of hepatitis C virus testing in the United States, 2013-2017. Clin Infect Dis 2019;68:1402-1405. doi: 10.1093/cid/ciy803.

[9] Belperio PS, Chartier M, Ross DB, Alaigh P, Shulkin D. Curing hepatitis C virus infection: Best practices from the U.S. Department of Veterans Affairs. Ann Intern Med 2017;167:499-504. doi: 10.7326/M17-1073. 
[10] Gane E, Kershenobich D, Seguin-Devaux C, Kristian P, Aho I, Dalgard O, et al. Strategies to manage hepatitis $C$ virus (HCV) infection disease burden volume 2. J Viral Hepat 2015;22 Suppl 1:46-73. doi: 10.1111/jvh.12352.

[11] World Health Organization. Global health sector strategies on viral hepatitis 2016-2021. Available from: https://www.who.int/hepatitis/strategy20162021/ghss-hep/en/.

[12] Saab S, Le L, Saggi S, Sundaram V, Tong MJ. Toward the elimination of hepatitis $C$ in the United States. Hepatology 2018;67:2449-2459. doi: 10. 1002/hep.29685.

[13] Waheed Y, Siddiq M, Jamil Z, Najmi MH. Hepatitis elimination by 2030: Progress and challenges. World J Gastroenterol 2018;24:4959-4961. doi: 10. 3748/wjg.v24.i44.4959.

[14] Irvin R, Ward K, Agee T, Nelson NP, Vellozzi C, Thomas DL, et al. Comparison of hepatitis $C$ virus testing recommendations in high-income countries. World J Hepatol 2018;10:743-751. doi: 10.4254/wjh.v10.i10.743.

[15] Litwin AH, Smith BD, Drainoni ML, McKee D, Gifford AL, Koppelman E, et al. Primary care-based interventions are associated with increases in hepatitis $C$ virus testing for patients at risk. Dig Liver Dis 2012;44:497-503. doi: 10 . 1016/j.dld.2011.12.014

[16] Satoskar R, Reau N. Potential consequences of healthcare recommendations: a focus on the U.S. Preventive Services Task Force. Hepatology 2013;58:422-427. doi: 10.1002/hep.26349.

[17] Rein DB, Smith BD, Wittenborn JS, Lesesne SB, Wagner LD, Roblin DW, et al. The cost-effectiveness of birth-cohort screening for hepatitis $C$ antibody in $U$. S. primary care settings. Ann Intern Med 2012;156:263-270. doi: 10. 7326/0003-4819-156-4-201202210-00378.

[18] MacDonald BR, Chu TC, Stewart RA, Ojha RP. Setting-based prioritization for birth cohort hepatitis $C$ virus testing in the United States. Clin Infect Dis 2020;70:543-544. doi: 10.1093/cid/ciz440.

[19] Defining the PCMH. Available from: https://pcmh.ahrq.gov/page/definingpcmh.

[20] Flanigan CA, Leung SJ, Rowe KA, Levey WK, King A, Sommer JN, et al. Evaluation of the impact of mandating health care providers to offer hepatitis $\mathrm{C}$ virus screening to all persons born during 1945-1965- New York, 2014. MMWR Morb Mortal Wkly Rep 2017;66:1023-1026.doi: 10.15585/mmwr mm6638a3.

[21] NYS Hepatitis C Testing Law. Available from: https://www.health.ny.gov/diseases/communicable/hepatitis/hepatitis_c/providers/testing_law.htm.

[22] Wong K, Abdelqader A, Camire L, Farshidpour M, Singh S, Abuwalla Z, et al. A resident initiative improves hepatitis $\mathrm{C}$ screening rates in primary care clinics. J Grad Med Educ 2017;9:768-770. doi: 10.4300/JGME-D-1700199.1.

[23] Aamar A, Madhani K, Singh P, Chia D. Hepatitis C screening: quality improvement in a resident continuity clinic. Gastroenterology 2017;152:S1168. doi: 10.1016/S0016-5085(17)33906-9.

[24] Madhani K. The integration of resident physicians in the outpatient management of chronic hepatitis C: Bridging the gap with primary care. Hepatology 2018;68:299A-300A.

[25] Jones $H$, Patel P, Sears D. Epic babyboomer reminders increase screening by 10 fold. Hepatology 2017;66:326A

[26] Kahn MQ, Majmudar K, Belopolsky Y, Beig MI, Yeboah-Korang A, Sonnenberg A et al. HCV age cohort screening follows a power-law distribution. Hepatology 2018;68:280A-281A.

[27] Soo S, Croghan A, Dale C, Spinelli T, Cardona Gonzalez MG, Hart ME, et al. Use of an automated health maintanence alert is associated with increased hepatitis $\mathrm{C}$ screening rates in an integrated medical group. Gastroenterology 2017; 152:S1171

[28] Federman AD, Kil N, Kannry J, Andreopolous E, Toribio W, Lyons J, et al. An electronic health record-based intervention to promote hepatitis $C$ virus testing among adults born between 1945 and 1965: A cluster-randomized trial. Med Care 2017;55:590-597. doi: 10.1097/MLR.0000000000000715.

[29] Nitsche B, Miller SC, Giorgio M, Berry CA, Muir A. Improving hepatitis C identification: technology alone is not the answer. Health Promot Pract 2018;19:506-512. doi: 10.1177/1524839917725501.

[30] Konerman MA, Thomson M, Gray K, Moore M, Choxi $H_{\text {, Seif }}$, et al. Impact of an electronic health record alert in primary care on increasing hepatitis $\mathrm{C}$ screening and curative treatment for baby boomers. Hepatology 2017;66: 1805-1813. doi: 10.1002/hep.29362.

[31] Teply R, Mukherjee S, Goodman M, Guck T. Impact of a hepatitis C virus electronic medical record screening alert for baby boomers. J Hepatol 2018;68:S327-S328.

[32] Yeboah-Korang A, Beig MI, Khan MO, Goldstein JL, Macapinlac DM, Maurer D, et al. Hepatitis C screening in commercially insured U.S. birth-cohort patients: Factors associated with testing and effect of an EMR-based screening alert. J Transl Int Med 2018;6:82-89. doi: 10.2478/jtim-2018-0012.

[33] Soo S, Mukhtar NA, Senussi N, Baxter L, Kowdley KV. Implementation of a health maintenance alert successfully increased rates of HCV screening across a large health care system serving the western United States. Hepatology 2018;68:306A.
[34] Al-Hihi E, Shankweiler C, Stricklen D, Gibson C, Dunn W. Electronic medical record alert improves HCV testing for baby boomers in primary care setting: adults born during 1945-1965. BMJ Open Qual 2017;6:e000084. doi: 10 1136/bmjoq-2017-000084.

[35] Turner B], Rochat A, Lill S, Bobadilla R, Hernandez L, Choi A, et al. Hepatitis C virus screening and care: Complexity of implementation in primary care practices serving disadvantaged populations. Ann Intern Med 2019. doi: 10.7326/M18-3573.

[36] Turner BJ, Taylor BS, Hanson JT, Perez ME, Hernandez L, Villarreal R, et al. Implementing hospital-based baby boomer hepatitis $C$ virus screening and linkage to care: Strategies, results, and costs. J Hosp Med 2015;10:510516. doi: 10.1002/jhm.2376

[37] Mehta A, Down C, Shen NT, Kumar S. Inpatient hepatitis C screening, health disparities, and inadequate linkage to outpatient care at a large academic medical center. Gastroenterology 2017;152:S1190.

[38] Shen NT, Rosenblatt R, Chan K, Mehta A, Johnston C, Ma X, et al. Impact of state law mandated hepatitis $C$ virus (HCV) screening and automated confirmatory testing on screening disparities and delivery of healthcare across medical and surgical departments. Hepatology 2018;68:279A-280A.

[39] Trowell J, Lowe G, Thuluvath PJ. Successful HCV screening among baby boomers using EMR pop-up and targeted mailing. Hepatology 2018;68: 896A-897A.

[40] Kruger DL, Rein DB, Kil N, Jordan C, Brown KA, Yartel A, et al. Implementation of birth-cohort testing for hepatitis C virus. Health Promot Pract 2017 18:283-289. doi: 10.1177/1524839916661495.

[41] Yartel AK, Rein DB, Brown KA, Krauskopf K, Massoud OI, Jordan C, et al. Hepatitis $C$ virus testing for case identification in persons born during 1945-1965: Results from three randomized controlled trials. Hepatology 2018;67:524-533. doi: 10.1002/hep.29548

[42] Abu-Heija A, Tama M, Kathi P, Naylor PH, Ehrinpreis MN, Mutchnick MG. High rate of $\mathrm{HCV}$ positive patients in an urban open access colonoscopy suite: potential point of care screening of a predominantly African American population. Hepatology 2018;68:894A.

[43] Abu-Heija A, Mohamad B, Tama M, Kathi PR, Nayeem MM, Khalid M, et al. Hepatitis C screening in the colonoscopy suite: patients are there, why don't we screen them? Gastroenterology 2019;156:S1338.

[44] Matin T, Shoreibah M, Williams W, Callaway J, Burksi C. Increasing hepatitis C screening rates in veteran population outside of the primary care setting. Gastroenterology 2018;154:S1201.

[45] Sears DM, Cohen DC, Ackerman K, Ma JE, Song J. Birth cohort screening for chronic hepatitis during colonoscopy appointments. Am J Gastroenterol 2013;108:981-989. doi: 10.1038/ajg.2013.50.

[46] Final recommendation statement: Hepatitis B virus infection: Screening, 2014. Avaliable from: https://www.uspreventiveservicestaskforce.org/Page/Document/RecommendationStatementFinal/hepatitis-b-virus-infectionscreening-2014.

[47] Hirode G, Liu B, Bhuket T, Wong R. Among 1945-1965 birth cohort patients with at least one additional hepatitis $C$ virus risk factor, one in eight were positive for $\mathrm{HCV}$ antibody: an underserved safety-net population experience. J Hepatol 2018;68:S316.

[48] Wong R, Campbell B, Liu B, Baden R, Bhuket T. Low rates of hepatitis C virus (HCV) testing and $\mathrm{HCV}$ awareness among individuals at high risk for chronic HCV infection among an underserved safety-net population. J Hepatol 2017; 66:S704-S705.

[49] Hirode G, Liu B, Bhuket T, Wong R. An outpatient endoscopy-based patient navigator model improves hepatitis $C$ virus screening among high risk patients: A 3-year prospective observational study among a safety-net health system. J Hepatol 2019;70:e497.

[50] Brillman JC, Crandall CS, Florence CS, Jacobs JL. Prevalence and risk factors associated with hepatitis C in ED patients. Am J Emerg Med 2002;20:476480. doi: 10.1053/ajem.2002.32642.

[51] Hall MR, Ray D, Payne JA. Prevalence of hepatitis C, hepatitis B, and human immunodeficiency virus in a Grand Rapids, Michigan emergency department. J Emerg Med 2010;38:401-405. doi: 10.1016/j.jemermed.2008.03.036.

[52] Kelen GD, Green GB, Purcell RH, Chan DW, Qaqish BF, Sivertson KT, et al. Hepatitis B and hepatitis C in emergency department patients. N Engl J Med 1992;326:1399-1404. doi: 10.1056/NEJM199205213262105.

[53] Minhas U, Matrachisia J, Picano JD, Martinez A. Hepatitis C screening in a high risk urban emergency department demonstrates high prevalence rates among birth cohort patients. Gastroenterology 2019;156:S-1340.

[54] Cornett JK, Bodiwala V, Razuk V, Shukla D, Narayanan N. Results of a hepatitis $C$ virus screening program of the 1945-1965 birth cohort in a large emergency department in New Jersey. Open Forum Infect Dis 2018;5 ofy065. doi: 10.1093/ofid/ofy065.

[55] Hsieh YH, Rothman RE, Laeyendecker OB, Kelen GD, Avornu A, Patel EU, et al. Evaluation of the Centers for Disease Control and Prevention recommendations for hepatitis $C$ virus testing in an urban emergency department. Clin Infect Dis 2016;62:1059-1065. doi: 10.1093/cid/ciw074.

[56] Lyons MS, Kunnathur VA, Rouster SD, Hart KW, Sperling MI, Fichtenbaum C], et al. Prevalence of diagnosed and undiagnosed hepatitis $C$ in a midwestern 
urban emergency department. Clin Infect Dis 2016;62:1066-1071. doi: 10. 1093/cid/ciw073.

[57] Allison WE, Chiang W, Rubin A, O'Donnell L, Saldivar MA, Maurantonio M, et al. Hepatitis C virus infection in the 1945-1965 birth cohort (baby boomers) in a large urban ED. Am J Emerg Med 2016;34:697-701. doi: 10.1016/j.ajem.2015.12.072.

[58] Galbraith JW, Franco RA, Donnelly JP, Rodgers JB, Morgan JM, Viles AF, et al. Unrecognized chronic hepatitis $C$ virus infection among baby boomers in the emergency department. Hepatology 2015;61:776-782. doi: 10.1002/hep. 27410.

[59] White DA, Anderson ES, Pfeil SK, Trivedi TK, Alter HJ. Results of a rapid hepatitis $C$ virus screening and diagnostic testing program in an urban emergency department. Ann Emerg Med 2016;67:119-128. doi: 10.1016/j. annemergmed.2015.06.023.

[60] Schechter-Perkins EM, Miller NS, Hall J, Hartman JJ, Dorfman DH, Andry C, et al. Implementation and preliminary results of an emergency department nontargeted, opt-out hepatitis $C$ virus screening program. Acad Emerg Med 2018;25:1216-1226. doi: 10.1111/acem.13484.

[61] Snelgrove CA. A quality improvement initiative: making hepatitis C screening a standard of care. Hepatology 2018;68:317A

[62] Hyun C, Hwang C, Lee S. HCV screening and linkage to care of baby boomers at community hospital emergency department using streamlined EHR ordering. Hepatology 2017;66:547A.

[63] Patel RC, Vellozzi C, Smith BD. Results of hepatitis C birth-cohort testing and linkage to care in selected U.S. sites, 2012-2014. Public Health Rep 2016; 131 Suppl 2:12-19. doi: 10.1177/00333549161310S203.

[64] Travis N, Fluker S, Miller L. Medical assistant driven improvement in hepatitis $C$ screening rates in the primary care setting. Hepatology 2018;68:308A.

[65] Dong BJ, Lopez M, Cocohoba J. Pharmacists performing hepatitis C antibody point-of-care screening in a community pharmacy: A pilot project. J Am Pharm Assoc (2003) 2017;57:510-515.e2. doi: 10.1016/j.japh.2017.04.463.

[66] Cartwright EJ, Rentsch C, Rimland D. Hepatitis C virus screening practices and seropositivity among US veterans born during 1945-1965. BMC Res Notes 2014;7:449. doi: 10.1186/1756-0500-7-449.

[67] Sarkar S, Esserman DA, Skanderson M, Levin FL, Justice AC, Lim JK. Disparities in hepatitis C testing in U.S. veterans born 1945-1965. J Hepatol 2016; 65:259-265. doi: 10.1016/j.jhep.2016.04.012.

[68] Ross DB, Belperio PS, Chartier M, Backus LI. Hepatitis C testing in U.S. veterans born 1945-1965: An update. J Hepatol 2017;66:237-238. doi: 10. 1016/j.jhep.2016.09.018.

[69] Justice AC, Esserman D, Sarkar S, Levin FL, Skanderson M, Lim JK. Reply to: "Hepatitis C testing in U.S. veterans born 1945-1965: An update". J Hepatol 2017;66:239. doi: 10.1016/j.jhep.2016.09.019.
[70] Testing for HCV. infection: an update of guidance for clinicians and laboratorians. MMWR Morb Mortal Wkly Rep 2013;62:362-365.

[71] Alter MJ, Kuhnert WL, Finelli L. Guidelines for laboratory testing and result reporting of antibody to hepatitis $C$ virus. Centers for Disease Control and Prevention. MMWR Recomm Rep 2003;52:1-13, 15; quiz CE1-4.

[72] Smith BD, Drobeniuc J, Jewett A, Branson BM, Garfein RS, Teshale E, et al. Evaluation of three rapid screening assays for detection of antibodies to hepatitis $C$ virus. J Infect Dis 2011;204:825-831. doi: 10.1093/infdis/jir422.

[73] Tang W, Chen W, Amini A, Boeras D, Falconer J, Kelly H, et al. Diagnostic accuracy of tests to detect Hepatitis $C$ antibody: a meta-analysis and review of the literature. BMC Infect Dis 2017;17:695. doi: 10.1186/s12879017-2773-2.

[74] Shivkumar S, Peeling R, Jafari Y, Joseph L, Pant Pai N. Accuracy of rapid and point-of-care screening tests for hepatitis $\mathrm{C}$ : a systematic review and metaanalysis. Ann Intern Med 2012;157:558-566. doi: 10.7326/0003-4819157-8-201210160-00006.

[75] Zou B, Yeo YH, Le MH, Henry L, Chang ET, Lok AS, et al. Prevalence of viremic hepatitis $C$ virus infection by age, race/ethnicity, and birthplace and disease awareness among viremic persons in the United States, 1999-2016. J Infect Dis 2020;221:408-418. doi: 10.1093/infdis/jiz479.

[76] Udompap P, Mannalithara A, Kwong AJ, Kim D, Kim WR. An alternative screening strategy for hepatitis $\mathrm{C}$ virus (HCV) infection among Americans not belonging in the baby boomer birth cohort. Gastroenterology 2017; 152:S1078.

[77] Eckman MH, Ward JW, Sherman KE. Cost effectiveness of universal screening for hepatitis $C$ virus infection in the era of direct-acting, pangenotypic treatment regimens. Clin Gastroenterol Hepatol 2019;17:930-939.e9. doi: 10. 1016/j.cgh.2018.08.080.

[78] Bian J, Schreiner AD. Population-based screening of hepatitis $C$ virus in the United States. Curr Opin Gastroenterol 2019;35:177-182. doi: 10. 1097/MOG.0000000000000520.

[79] Draft recommendation statement: Hepatitis $C$ virus infection in adolescents and adults: Screening. Available from: https://www.uspreventiveservicestaskforce.org/Page/Document/draft-recommendation-statement/hepatitisc-screening1.

[80] Center for Disease Control and Prevention. Recommendations for hepatitis C screening among adults-2019; Request for comment. Available from: https: //www.federalregister.gov/documents/2019/10/28/2019-23521/recommendations-for-hepatitis-c-screening-among-adults-2019-request-forcomment.

[81] AASLD-IDSA HCV guidance: Recommendations for testing, managing, and treating hepatitis C. Available from: https://www.hcvguidelines.org/. 